Original article

\title{
Latent profiles of family background, personality and mental health factors and their association with behavioural addictions and substance use disorders in young Swiss men
}

\author{
Simon Marmet ${ }^{\mathrm{a}, *}$, Joseph Studer ${ }^{\mathrm{a}}$, Ansgar Rougemont-Bücking ${ }^{\mathrm{a}}$, Gerhard Gmel ${ }^{\mathrm{a}, \mathrm{b}, \mathrm{c}, \mathrm{d}}$ \\ a Alcohol Treatment Centre, Lausanne University Hospital/CHUV, Switzerland \\ ${ }^{\mathrm{b}}$ Addiction Switzerland, Lausanne, Switzerland \\ ${ }^{\mathrm{c}}$ Centre for Addiction and Mental Health, Toronto, Canada \\ ${ }^{\mathrm{d}}$ University of the West of England, Bristol, United Kingdom
}

\section{A R T I C L E I N F O}

\section{Article history:}

Received 9 January 2018

Received in revised form 6 April 2018

Accepted 7 April 2018

Available online 4 May 2018

\section{Keywords:}

Substance use disorders

Behavioural addictions

Affective disorders

Attention deficit - hyperactivity disorder

(ADHD)

Borderline personality disorder

Stress

\begin{abstract}
A B S T R A C T
Background: Recent theories suggest that behavioural addictions and substance use disorders may be the result of the same underlying vulnerability. The present study investigates profiles of family background, personality and mental health factors and their associations with seven behavioural addictions (to the internet, gaming, smartphones, internet sex, gambling, exercise and work) and three substance use disorder scales (for alcohol, cannabis and tobacco).

Methods: The sample consisted of 5287 young Swiss men (mean age =25.42) from the Cohort Study on Substance Use Risk Factors (C-SURF). A latent profile analysis was performed on family background, personality and mental health factors. The derived profiles were compared with regards to means and prevalence rates of the behavioural addiction and substance use disorder scales.

Results: Seven latent profiles were identified, ranging from profiles with a positive family background, favourable personality patterns and low values on mental health scales to profiles with a negative family background, unfavourable personality pattern and high values on mental health scales. Addiction scale means, corresponding prevalence rates and the number of concurrent addictions were highest in profiles with high values on mental health scales and a personality pattern dominated by neuroticism. Overall, behavioural addictions and substance use disorders showed similar patterns across latent profiles. Conclusion: Patterns of family background, personality and mental health factors were associated with different levels of vulnerability to addictions. Behavioural addictions and substance use disorders may thus be the result of the same underlying vulnerabilities.
\end{abstract}

(C) 2018 Elsevier Masson SAS. All rights reserved.

\section{Introduction}

Schaffer et al. [1] proposed that substance use disorders (SUDs) and behavioural addictions (BAs) may be expressions of an underlying addiction syndrome related with several distal neurobiological, genetic, psychological and social risk factors. In this line of thinking, the present study investigates the link between clusters of individuals with different family backgrounds, personality and mental health factors, with seven BAs (to the internet, gaming, smartphones, internet sex, gambling, exercise and work) and three SUDs (for alcohol, cannabis and tobacco), in a large sample of young Swiss men, among whom substance use [2] and

\footnotetext{
* Corresponding author at: Service d'Alcoologie, P2.01.113, Avenue de Beaumont 21b, CH-1011 Lausanne, Switzerland.

E-mail address: simon.marmet@chuv.ch (S. Marmet).
}

other potentially addictive behaviours $[3,4]$ are widespread. There is an ongoing debate about whether some of the so-called behavioural addictions should actually be pathologized as "addictions" [5]. Currently, only gambling is an accepted disorder in DSM-5 [6], and internet gaming will likely be included in ICD-11 [7]. However, for ease of presentation, all included potential problematic behaviours will be labelled as behavioural addictions in this paper. In contrast to measuring quantity or frequency of use only, measures for SUDs and BAs are based on symptoms of problematic use like tolerance, withdrawal, salience as well as personal and social consequences [8]. The main research question was whether there are distinct profiles of family background, personality and mental health factors associated with SUDs or BAs.

There are many studies about correlates of BAs and SUDs. Family-related variables (good family relationships and management) have been shown to be associated with lower substance use in young adults [9], and there is also evidence for parental 
monitoring being associated with lower prevalence rates of BAs, such as problematic gambling [10] and internet addiction [11]. In the field of personality, a meta-analysis by Kotov et al. [12] found that the traits of neuroticism and disinhibition were positively related to SUDs, whereas the trait of conscientiousness was negatively related to SUDs. Extraversion was found to be negatively related to drug use only, and agreeableness was negatively related to drug and mixed substance use. In a study involving 218 university students, Andreassen et al. [13] found that $6 \%-17 \%$ of the variance in seven BAs was explained by the five-factor model of personality. Finally, for mental health factors, there is a broad range of studies linking mental disorders to SUDs $[1,14,15]$. As an example for BAs, Ko et al. [16] found that internet addiction was related to attention-deficit hyperactivity disorder (ADHD), depressive disorder and social phobia. However, the association between mental functioning and addiction is complex: mental health factors may increase the risk for addictions or vice versa, or they may share some risk factors $[15,17]$.

Shaffer et al. [1] identified shared psychological manifestations and sequelae of different addictions (e.g. feelings of guilt, shame, tolerance and withdrawal), parallel natural histories (patterns of onset, improvement, relapse and remission), object non-specificity, concurrent manifestations of addictions and treatment non-specificity and they therefore put forward the idea of an addiction syndrome. In this interpretation, addictive disorders are seen less as the consequences of exposure to a specific substance or behaviour, but may instead be seen as expressions of an underlying vulnerability.

Comparing BAs to SUDs, Grant et al. [18] found common features, notably in natural history (e.g. chronic, relapsing patterns), phenomenology (e.g. craving, resulting positive mood state) and adverse consequences (e.g. financial or marital problems); they also found that they may respond to similar psychological treatments and pharmacological treatments. A recent study assessing four substance and six behavioural addictions also found that the 10 scales loaded highly on a single component, providing thus evidence for an underlying addiction construct [19].

Although there are several studies linking individual risk factors to specific addictions, to the best of our knowledge, there are no studies linking patterns of potential risk factors to multiple addictions. We therefore investigated profiles of family background, personality and mental health factors that may contribute to the occurrence or co-occurrence of addictions using latent profile analysis (LPA). LPA is a person-centred, model based clustering approach (in contrast to e.g. k-means clustering; see [20] for a comparison of LCA/LPA with other clustering approaches) capable of assembling participants into distinct profiles, based on their expressions on a number of variables, whereby allowing the inclusion of covariates and the handling of non-normal data [21]. The aim of this study was therefore not to test associations between specific variables and addictions as in a variable-centred approach, but to identify groups of individuals sharing similar characteristics (person-centred approach). Within this framework, we investigated whether a) different profiles of potential risk factors (namely, family background, personality and mental health factors) could be identified, b) addictions scales differed across the profiles identified; and c) differences between profiles were associated with different types of addictions (i.e. BAs and SUDs).

\section{Method}

\subsection{Sample}

The present work's sample came from the Cohort Study on Substance Use Risk Factors (C-SURF; for an overview see [2]), a longitudinal study designed to examine use patterns and associated factors in young Swiss men. Enrolment for the baseline measurement occurred between August 2010 and November 2011 in three of Switzerland's six military recruitment centres, located in Lausanne (French-speaking: $57.4 \%$ of the final sample), Windisch and Mels (German-speaking: 42.6\%), during the military recruitment procedures which are mandatory for all Swiss men. Written consent to participate in the study was given by 7556 young men; 5987 (79.2\%) returned the baseline questionnaire between September 2010 and March 2012; 5362 returned the second follow-up questionnaire between April 2016 and September 2017. Questions about family background were asked at baseline only and assumed to be stable across waves; the personality, mental health and addiction measures stem from the second follow-up questionnaire. Data from first follow-up were not used. The final sample of 5287 included all participants who had replied to the second follow-up questionnaire. 75 Individuals were excluded because of more than four missing values across variables used in the latent profile model. Mean age at baseline was 19.97 years $(S D=1.22)$ and 25.42 years $(S D=1.23)$ at the second follow-up. The research protocol was approved by the Human Research Ethics Committee of the Canton Vaud (Protocol No. 15/07).

\subsection{Measurements}

\subsubsection{Family background}

Family situation was assessed with a question about how participants lived most of the time before they were 18 years old. Responses were "grew up with both parents, or one parent and one step-parent", and "grew up with one parent or no parents". Parental divorce before 18 years old was assessed using a yes/no question. These questions were adapted from the Alcohol Use Disorder and Associated Disabilities Interview Schedule IV (AUDADIS IV) [22]. Participant's satisfaction with his relationship with parents before the age of 18 was averaged across mother and father on a 5-point scale ranging from "not at all satisfied" to "very satisfied". Parenting during childhood was measured using six statements (two each for parental regulation, monitoring and support at the age of 15) with five-point Likert scale-type response options ranging from "almost never" to "almost always". These questions were adapted from the European School Survey Project on Alcohol and Other Drugs [23].

\subsubsection{Personality}

Three of five subscales from the Zuckermann-Kuhlmann Personality Questionnaire [24] were used: a) aggression/hostility, b) sociability and c) neuroticism/anxiety. Each subscale was measured using ten true/false questions. Sensation seeking was measured using the Brief Sensation Seeking Scale [25] with eight items on a five-point Likert scale ("strongly agree" to "strongly disagree").

\subsubsection{Mental health}

Stress symptoms during the last month were measured using the Perceived Stress Scale 10 (PSS10) [26], consisting of ten statements describing stressful situations in life using five-point Likert scale-type response options ranging from "never" to "very often".

Social anxiety symptoms during the last week were measured using the Clinically Useful Social Anxiety Disorder Outcome Scale [27], consisting of 12 statements rated using five-point Likert scale-type response options ranging from "almost never true" to "almost always true".

Borderline personality disorder symptoms were measured using the Mclean Screening Instrument for Borderline Personality Disorder [28,29], consisting of ten true/false statements. 
Adult attention-deficit hyperactivity disorder (ADHD) symptoms during the last 12 months were measured using the six-item five-point Likert scale (from "never" to "very often") screener version of the Adult ADHD Self-Report Scale [30].

Bipolar disorder (lifetime) was measured using the Mood Disorder Questionnaire [31] (French version adapted from [32]). Participants had to endorse at least seven of the 13 symptoms [31], and some symptoms had to occur in the same time frame and had to cause at least moderate problems. Due to this coding practice, this scale was used only as a dichotomous indicator for the main analysis.

Major depression symptoms in the last two weeks were measured using the Major Depressive Inventory (WHO-MDI) [33], consisting of 12 six-point Likert-type statements ranging from "never" to "always".

\subsubsection{Behavioural addiction and substance use disorder scales}

Internet (14 items) [34,35], gaming (last 6 months; 7 items) [36], smartphone (10 items) [37,38], exercise (6 items) [39] and work addiction (last 12 months; 7 items) [40] were measured using Likert-type scales. Although there is some criticism on the concept of work addiction, Griffiths et al. [41] concluded that "work addiction fits very well into recently postulated criteria for conceptualization of a behavioural addiction"[41], and was seen to be "beyond the phase of proof of concept" [42]. Online sexual compulsivity was measured using the internet sex addiction scale (last 12 months) [43,44] using six true/false statements, and gambling disorder (last 12 months) was measured using 9 yes/no items representing the DSM-5 criteria [45,46].

Alcohol use disorder (last 12 months) was measured using 11 DSM-5 criteria $[22,45,47]$ in a yes/no format. Cannabis use disorder (last 12 months) was measured using the revised version of the Cannabis Use Disorder Identification Test (10 items [48], based on [49]). Finally, tobacco dependence (last 12 months) was assessed using the Fagerström Test for Nicotine Dependence (6 items) [50].

In the main analysis, scale summary scores were used, except for measurements of family situation, parental divorce and bipolar disorder measures (dichotomous). Missing values on items were replaced by the mean of the other items in the respective scales. For participants with more than $20 \%$ of a scale's items missing, the scale score was recorded as missing.

\subsection{Statistical analysis}

To identify homogenous subgroups of participants with different patterns of family background, personality and mental health factors, LPA was conducted using Mplus 8 [51]. LPA models with two to eight profiles were fitted. Entropy, log-likelihood, Akaike Information Criteria (AIC) and Bayesian Information Criteria (BIC) were compared across the solutions to determine the optimal number of profiles. Vuong-Lo-Mendell-Rubin likelihood ratio tests (LRT) and Lo-Mendell-Rubin adjusted LRT [52] were performed to estimate whether a model with $k$ profiles fitted the data significantly better than a model with $k-1$ profiles. The three binary variables (parental separation, family situation and bipolar disorder) were entered into the model as categorical variables. Social anxiety and borderline disorder symptoms were entered using a zero-inflated negative binomial distribution and the other variables as normally distributed continuous variables. For participants with missing values all available information was used for profile classification [51]; model parameters did not change considerably when participants with missing data were excluded.

After identification of the optimal number of profiles, differences in means of the addiction scales across profiles were tested using the Bolck-Croon-Hagenaars $(\mathrm{BCH})$ procedure $[53,54]$ in Mplus, taking measurement error of profile membership into account. Significance tests for prevalence rates of the addictions were done using the Lanza method for categorical data (DCAT) [55]. Profile plots across the variables used and addiction scale scores are provided, and z-standardisation (mean $=0 ; \mathrm{SD}=1$ ) was used for the sake of comparability across scales.

\section{Results}

The Vuong-Lo-Mendell-Rubin LRT ( $p=.130$ for seven versus eight profiles) and the Lo-Mendell-Rubin adjusted LRT ( $p=.132$ for eight versus seven profiles) indicated a seven-profile solution (Table 1). Table 2 shows the model results for the indicator variables in the LPA model. Fig. 1 shows the z-standardised means of the indicator variables for each profile.

Overall, mental health declined on all the scales from profile 1 (labelled "privileged") to profile 7 (labelled "vulnerable"), the latter having high values indicating poor mental health on all scales, particularly major depression. For personality traits, two main patterns were identified as deviating from the average. The first pattern had high aggression/hostility, high neuroticism/ anxiety and low sociability (profiles 5, 7 and moderately 4). The second pattern was the inverse: low aggression/hostility, low neuroticism/anxiety and high sociability (profile 1, and profile 2 to a lesser degree). Two profiles were distinguished by family background: a) high parental divorce rates and a family situation before the age of 18 with only one or no parent in the "parental separation" profile (2); b) a poor relationship with parents before the age of 18 and poor parenting at the age of 15 in the "family difficulties" profile (4).

Table 3 shows the means and prevalence rates of the addiction scales for each latent profile, as well as the average number of addictions and the percentage of participants with at least one addiction in the respective profiles. Fig. 2 shows the $z$-standardised means of the addiction scales across profiles; significance tests for mean differences and prevalence rates between classes are shown

Table 1

Model statistics for two-profile to eight-profile solutions used for deciding on the number of profiles.

\begin{tabular}{|c|c|c|c|c|c|c|c|}
\hline & \multicolumn{7}{|c|}{ Number of latent profiles } \\
\hline & 2 & 3 & 4 & 5 & 6 & 7 & 8 \\
\hline Free Parameters & 44 & 61 & 78 & 95 & 112 & 129 & 146 \\
\hline Log-likelihood HO Value & $-148,477$ & $-147,229$ & $-146,529$ & $-145,928$ & $-145,325$ & $-144,961$ & $-144,723$ \\
\hline Akaike Information Criteria (AIC) & 297,043 & 294,581 & 293,214 & 292,046 & 290,874 & 290,180 & 289,738 \\
\hline Bayesian Information Criteria (BIC) & 297,332 & 294,982 & 293,726 & 292,671 & 291,610 & 291,028 & 290,698 \\
\hline Adjusted BIC & 297,192 & 294,788 & 293,479 & 292,369 & 291,254 & 290,618 & 290,234 \\
\hline Vuong-Lo-Mendell-Rubin Likelihood Ratio Test (LRT) $p$-value & $<0.001$ & 0.017 & $<0.001$ & 0.033 & 0.001 & $<\mathbf{0 . 0 0 1}$ & 0.130 \\
\hline Lo-Mendell-Rubin Adjusted LRT p-value & $<0.001$ & 0.017 & $<0.001$ & 0.035 & 0.001 & $<\mathbf{0 . 0 0 1}$ & 0.132 \\
\hline Entropy & 0.881 & 0.826 & 0.833 & 0.797 & 0.825 & 0.820 & 0.815 \\
\hline
\end{tabular}

Note: The selected model is in bold. 
Table 2

Means for continuous variables and percentages for binary indicator variables, by profile.

\begin{tabular}{|c|c|c|c|c|c|c|c|c|c|}
\hline & \multicolumn{7}{|l|}{ Profile } & \multicolumn{2}{|l|}{ Total } \\
\hline & $\begin{array}{l}1 . \\
\text { Privileged }\end{array}$ & $\begin{array}{l}2 . \\
\text { Parental } \\
\text { separation }\end{array}$ & $\begin{array}{l}3 . \\
\text { Normative }\end{array}$ & $\begin{array}{l}4 . \\
\text { Family } \\
\text { difficulties }\end{array}$ & $\begin{array}{l}5 . \\
\text { High } \\
\text { neuroticism }\end{array}$ & 6. Depressive & 7. Vulnerable & $\begin{array}{l}\text { Mean/ } \\
\%\end{array}$ & SD \\
\hline $\mathrm{n}$ & $\begin{array}{l}1555 \\
(29.4 \%)\end{array}$ & $531(10.0 \%)$ & $\begin{array}{l}1801 \\
(34.1 \%)\end{array}$ & $341(6.4 \%)$ & $602(11.4 \%)$ & $249(4.7 \%)$ & $208(3.9 \%)$ & & \\
\hline \multicolumn{10}{|l|}{ Family background } \\
\hline $\begin{array}{l}\text { Family situation } \\
\text { (\% not both parents) }\end{array}$ & $1.6 \%$ & $84.8 \%$ & $2.0 \%$ & $43.5 \%$ & $12.0 \%$ & $16.5 \%$ & $24.7 \%$ & $15.6 \%$ & \\
\hline Parental divorce (\%) & $8.2 \%$ & $98.6 \%$ & $9.9 \%$ & $59.4 \%$ & $21.9 \%$ & $25.6 \%$ & $31.5 \%$ & $24.4 \%$ & \\
\hline $\begin{array}{l}\text { Relationship with } \\
\text { parents }(0-4)\end{array}$ & 3.52 & 2.96 & 3.38 & 1.91 & 3.18 & 3.12 & 2.58 & 3.22 & 0.82 \\
\hline Parenting (0-24) & 19.78 & 18.46 & 19.19 & 13.20 & 18.86 & 17.98 & 16.70 & 18.72 & 4.05 \\
\hline $\begin{array}{l}\text { Summary family } \\
\text { background }\end{array}$ & $\begin{array}{l}\text { best } \\
\text { situation }\end{array}$ & $\begin{array}{l}\text { separated } \\
\text { parents }\end{array}$ & average & $\begin{array}{l}\text { bad relationship } \\
\text { with parents, } \\
\text { poor parenting }\end{array}$ & average & average & $\begin{array}{l}\text { below } \\
\text { average }\end{array}$ & & \\
\hline \multicolumn{10}{|l|}{ Personality } \\
\hline $\begin{array}{l}\text { Neuroticism/anxiety } \\
\quad(0-10)\end{array}$ & 0.77 & 1.22 & 1.87 & 2.69 & 5.75 & 2.32 & 6.95 & 2.20 & 2.17 \\
\hline $\begin{array}{l}\text { Aggression/hostility } \\
\text { (0-10) }\end{array}$ & 3.04 & 3.46 & 3.90 & 4.60 & 4.61 & 3.98 & 5.13 & 3.78 & 2.15 \\
\hline $\begin{array}{l}\text { Sociability } \\
\quad(0-10)\end{array}$ & 5.73 & 5.24 & 4.81 & 4.05 & 4.00 & 5.01 & 3.44 & 4.94 & 2.24 \\
\hline $\begin{array}{l}\text { Sensation seeking } \\
\quad(0-32)\end{array}$ & 14.96 & 15.78 & 16.29 & 17.44 & 16.44 & 15.47 & 17.41 & 15.95 & 6.48 \\
\hline Summary personality & $\begin{array}{l}\text { low } \mathrm{N} \text { and } \\
\mathrm{A} \text {, high } \mathrm{S}\end{array}$ & $\begin{array}{l}\mathrm{N} \text { below } \\
\text { average }\end{array}$ & average & $\begin{array}{l}\text { Moderately- } \\
\text { high } \mathrm{N} \text { and } \mathrm{A} \text {, } \\
\text { low S }\end{array}$ & $\begin{array}{l}\text { high } \mathrm{N} \text { and } \\
\text { A, low } \mathrm{S}\end{array}$ & average & $\begin{array}{l}\text { high } \mathrm{N} \text { and } \\
\text { A, low S }\end{array}$ & & \\
\hline \multicolumn{10}{|l|}{ Mental health } \\
\hline Bipolar disorder (\%) & $0.0 \%$ & $0.9 \%$ & $0.9 \%$ & $7.9 \%$ & $6.1 \%$ & $5.1 \%$ & $18.8 \%$ & $2.6 \%$ & \\
\hline ADHD $(0-24)$ & 4.54 & 5.74 & 7.22 & 8.78 & 9.58 & 7.45 & 12.22 & 6.86 & 4.21 \\
\hline $\begin{array}{l}\text { Social anxiety } \\
\qquad(0-48)\end{array}$ & 1.21 & 3.31 & 8.43 & 8.83 & 16.11 & 10.40 & 20.57 & 7.55 & 8.26 \\
\hline $\begin{array}{l}\text { Perceived stress } \\
\quad(0-40)\end{array}$ & 9.09 & 10.81 & 13.42 & 15.52 & 18.74 & 18.41 & 24.43 & 13.29 & 5.96 \\
\hline $\begin{array}{l}\text { Borderline } \\
\quad(0-10)\end{array}$ & 0.13 & 0.61 & 1.38 & 3.19 & 3.85 & 2.45 & 6.12 & 1.72 & 2.18 \\
\hline $\begin{array}{l}\text { Major depression } \\
\quad(0-50)\end{array}$ & 3.92 & 5.85 & 7.31 & 10.97 & 12.02 & 24.30 & 30.04 & 8.64 & 7.40 \\
\hline $\begin{array}{l}\text { Summary mental } \\
\text { health }\end{array}$ & Best & $\begin{array}{l}\text { below } \\
\text { average }\end{array}$ & average & $\begin{array}{l}\text { somewhat above } \\
\text { average }\end{array}$ & $\begin{array}{l}\text { high on stress, } \\
\text { social anxiety, } \\
\text { borderline }\end{array}$ & $\begin{array}{l}\text { high on } \\
\text { depression }\end{array}$ & $\begin{array}{l}\text { poor mental } \\
\text { health }\end{array}$ & & \\
\hline
\end{tabular}

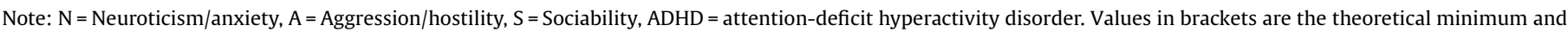
maximum of the scales.

in Supplementary Table 1 . Table 4 presents a summary of profile characteristics and their association with the addiction scales. Addiction scale means generally increased across groups, being lowest in the "privileged" profile (1), and highest in the "vulnerable" profile (7). Similarly, 20.2\% had at least one addiction in profile 1 versus $88.6 \%$ in profile 7 . The difference between the extreme profiles ( 1 and 7 ) were all highly significant $(p<0.001)$, and often the differences were even significant between adjacent profiles (see Supplementary Table 1). Deviations from this general tendency of increasing addiction mean scales with increasing vulnerabilities were mainly found for profile 5 (high neuroticism) and 6 (depressive). The "highl neuroticism" profile was particularly high on technology addiction but relatively low on cannabis and tobacco addiction, whereas the depressive profile was particularly high on gaming, work and tobacco addiction.

\section{Discussion}

The present work identified seven profiles of family background, personality and mental health factors, which were subsequently associated with increasing values on the addiction scales between profile 1 and profile 7 . Profile 1 ("privileged") showed the lowest mean values on all the addiction scales, whereas profile 7 ("vulnerable") showed the highest mean values on all the addiction scales. Strikingly, this was true for all BAs (with the exception of exercise addiction) and all SUDs. This may indicate that the addictions studied share common vulnerabilities that may not be specific to SUD or BA, but rather to addiction in general. This is in line with the addiction syndrome concept [1], which implies that there are groups of people with a latent addiction syndrome caused by several etiological factors, leading to expressions of different forms of addictions. Further support for the addiction syndrome hypothesis comes from the fact that addictions tend to co-occur, especially in the more vulnerable profiles (4 to 7). This does, according to Shaffer et al. (p. 371) [1], "... suggest the presence of an underlying force responsible for addiction". Other concepts implying commonalities between BAs and SUDs were also proposed by Griffiths [8] (the component model) and by Blum et al. [56], using the term Reward Deficiency Syndrome. The Reward Deficiency Syndrome, based on evidence of the importance of dopaminergic pathways in different addictions, may be a possible explanation for the link between BAs and SUDs [56].

With regards to personality, we found that a pattern of high values for the traits of neuroticism/anxiety and aggression/ hostility (and high sensation-seeking values in profile 7), but low values for the trait of sociability was associated with aboveaverage ratings on the addiction scales (profiles 7, 5 and, to a lesser degree 4). Such a pattern had previously been found in a subsample of cocaine users, where it was also associated with psychiatric 


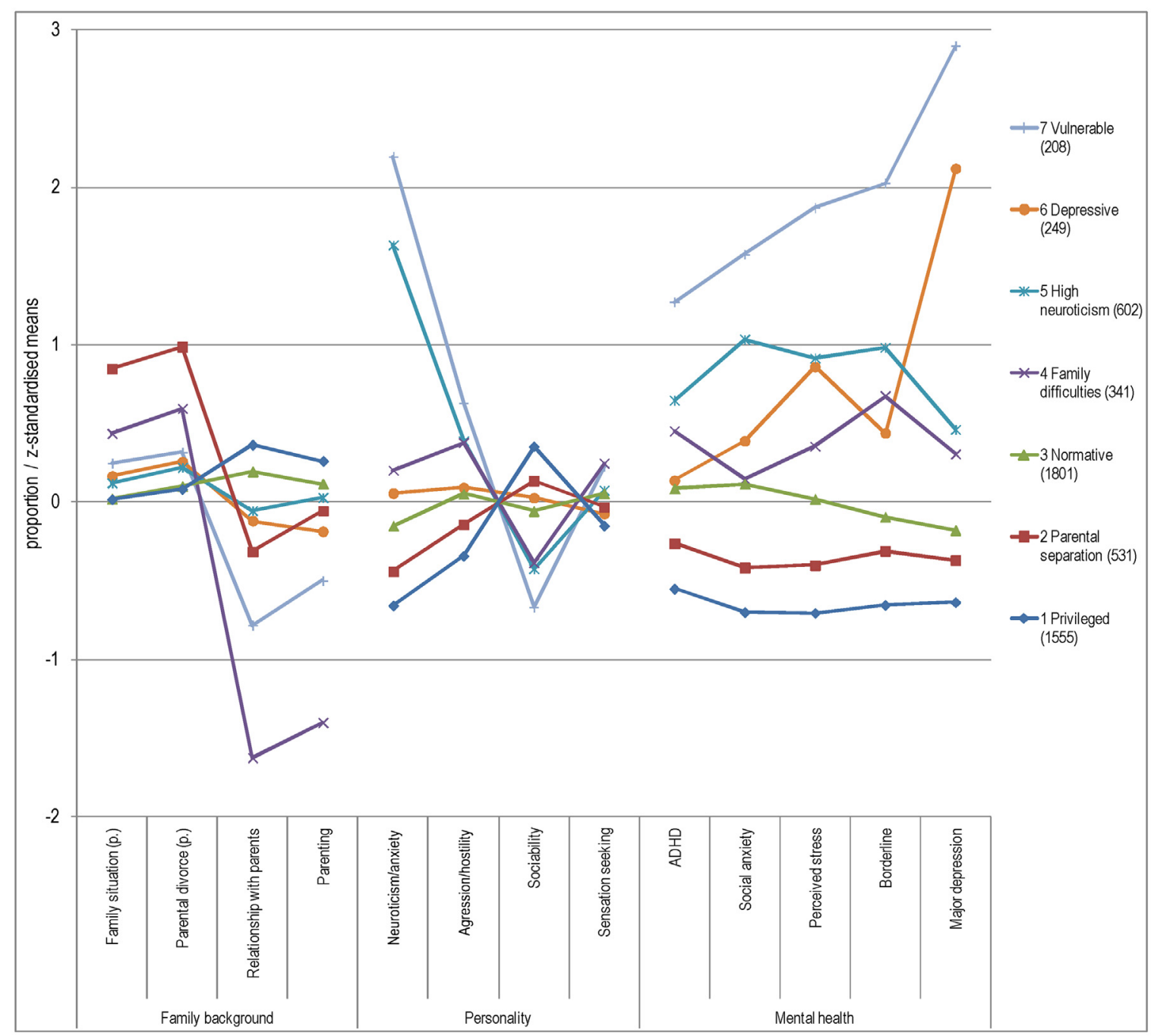

Fig. 1. Graphical summary of profiles.

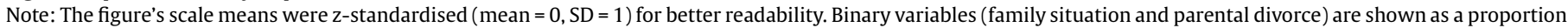

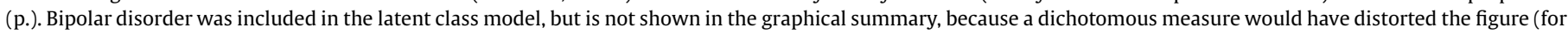
values see Table 2 ). ADHD = attention-deficit hyperactivity disorder.

comorbidities [57]. Interestingly, the inverse personality pattern was found in the privileged profile, which was associated with lower than average ratings on the addiction scales. These findings provide further evidence that the well-known link between personality and SUDs [58,59] may extend to BAs as well.

In addition to this general tendency, there were three specificities: First, the LPA showed that the "family difficulties" profile (4), with poor parental relationships before the age of 18 and poor parenting at age 15 , was associated with intermediate values on the addiction scales. This was in line with other research showing that family relationships and functioning in adolescence are related to subsequent substance use in emerging adulthood [60]. In contrast, the "parental separation" profile (2), with its high parental divorce rates before the age of 18 but few familial difficulties, did not result in an increased risk of addictions, which has been reported in a previous C-SURF study for excessive alcohol consumption [61]. Research to date has found that parental separation may be a risk factor for substance use in adolescence [62], although the findings for emerging adulthood were somewhat mixed [60]. In young Swiss men, parental separation is not a risk factor for addictions unless combined with poor family functioning. This confirms work that parental divorce no longer predicted adolescent alcohol use if controlled for conflict between the parents and the adolescent. They concluded that conflicts between parents and adolescents, but not conflicts between parents, were predictive of adolescent substance use [63]. This may hold for BAs as well and extend to emerging adulthood.

Second, the "highl neuroticism" profile (5), with its higher values for the traits of neuroticism/anxiety and aggression/ hostility but low values for the trait of sociability combined with high social anxiety, was associated with particularly high values on the technological addiction scales (internet, gaming, smartphone, internet sex). This may point to a group of young men with problems with social interactions who more regularly seek relief or support in online activities and are more prone to addiction in online environments, as has been suggested by Caplan [64]. An association between problematic internet use and social anxiety has also been reported previously $[16,65,66]$.

Third, the "depressive" profile (6) was remarkable in that it combined high values for major depression and slightly higher than average values on the perceived stress scale, whereas the other mental health factors were not particularly high and the personality traits were around average. This profile was associated with moderately increased mean values on the addiction scales, particularly work, gaming, and tobacco addiction. 
Table 3

Means, standard error and prevalence (in\%) for behavioural addiction and substance use disorder scales, by profile.

\begin{tabular}{|c|c|c|c|c|c|c|c|c|}
\hline & \multicolumn{8}{|l|}{ Profile } \\
\hline & 1. Privileged & $\begin{array}{l}\text { 2. Parental } \\
\text { separation }\end{array}$ & 3. Normative & $\begin{array}{l}\text { 4. Family } \\
\text { difficulties }\end{array}$ & $\begin{array}{l}\text { 5. High } \\
\text { neuroticism }\end{array}$ & 6. Depressive & 7. Vulnerable & Total \\
\hline $\mathrm{n} /(\%)$ & $\begin{array}{l}1555 \\
(29.4 \%)\end{array}$ & $531(10.0 \%)$ & $\begin{array}{l}1801 \\
(34.1 \%)\end{array}$ & $\begin{array}{l}341 \\
(6.4 \%)\end{array}$ & $\begin{array}{l}602 \\
(11.4 \%)\end{array}$ & $\begin{array}{l}249 \\
(4.7 \%)\end{array}$ & $\begin{array}{l}208 \\
(3.9 \%)\end{array}$ & 5287 \\
\hline \multicolumn{9}{|l|}{$\begin{array}{l}\text { Internet } \\
(0-56)\end{array}$} \\
\hline mean & 4.22 & 6.84 & 10.18 & 12.63 & 14.51 & 11.83 & 18.97 & 9.17 \\
\hline S.E. & 0.17 & 0.35 & 0.24 & 0.68 & 0.48 & 0.81 & 0.92 & 0.12 \\
\hline$\%$ & $0.0 \%$ & $0.0 \%$ & $3.9 \%$ & $8.0 \%$ & $12.0 \%$ & $11.7 \%$ & $25.1 \%$ & $4.7 \%$ \\
\hline \multicolumn{9}{|l|}{$\begin{array}{l}\text { Gaming } \\
(0-28)\end{array}$} \\
\hline mean & 1.61 & 2.96 & 3.35 & 4.58 & 4.8 & 4.95 & 7.37 & 3.28 \\
\hline S.E. & 0.08 & 0.18 & 0.11 & 0.34 & 0.24 & 0.42 & 0.52 & 0.06 \\
\hline$\%$ & $1.2 \%$ & $4.2 \%$ & $5.5 \%$ & $13.3 \%$ & $13.0 \%$ & $17.4 \%$ & $27.4 \%$ & $6.9 \%$ \\
\hline \multicolumn{9}{|c|}{$\begin{array}{l}\text { Smartphone } \\
(0-50)\end{array}$} \\
\hline mean & 4.56 & 6.79 & 9.14 & 9.6 & 12.12 & 8.75 & 12.7 & 8.05 \\
\hline S.E. & 0.17 & 0.37 & 0.22 & 0.58 & 0.43 & 0.63 & 0.77 & 0.11 \\
\hline$\%$ & $0.9 \%$ & $5.1 \%$ & $9.0 \%$ & $11.2 \%$ & $18.7 \%$ & $8.8 \%$ & $25.4 \%$ & $8.1 \%$ \\
\hline \multicolumn{9}{|c|}{$\begin{array}{l}\text { Internet sex } \\
\quad(0-6)\end{array}$} \\
\hline mean & 0.29 & 0.4 & 0.62 & 0.91 & 1.05 & 0.79 & 1.2 & 0.6 \\
\hline S.E. & 0.02 & 0.05 & 0.03 & 0.09 & 0.06 & 0.09 & 0.1 & 0.01 \\
\hline$\%$ & $2.1 \%$ & $3.9 \%$ & $6.4 \%$ & $14.1 \%$ & $14.8 \%$ & $10.5 \%$ & $19.4 \%$ & $7.0 \%$ \\
\hline \multicolumn{9}{|c|}{$\begin{array}{l}\text { Gambling } \\
(0-9)\end{array}$} \\
\hline mean & 0.03 & 0.09 & 0.11 & 0.21 & 0.27 & 0.32 & 0.49 & 0.13 \\
\hline S.E. & 0.01 & 0.03 & 0.02 & 0.06 & 0.05 & 0.08 & 0.09 & 0.01 \\
\hline$\%$ & $0.2 \%$ & $1.0 \%$ & $0.7 \%$ & $1.9 \%$ & $3.7 \%$ & $3.8 \%$ & $6.3 \%$ & $1.4 \%$ \\
\hline \multicolumn{9}{|l|}{$\begin{array}{l}\text { Work } \\
(0-28)\end{array}$} \\
\hline mean & 6.39 & 7.39 & 9.05 & 9.86 & 10.89 & 11.82 & 12.49 & 8.63 \\
\hline S.E. & 0.12 & 0.23 & 0.13 & 0.34 & 0.24 & 0.39 & 0.42 & 0.07 \\
\hline$\%$ & $2.1 \%$ & $4.3 \%$ & $7.4 \%$ & $7.8 \%$ & $15.7 \%$ & $21.1 \%$ & $29.2 \%$ & $8.0 \%$ \\
\hline \multicolumn{9}{|l|}{$\begin{array}{l}\text { Exercise } \\
(0-24)\end{array}$} \\
\hline mean & 5.99 & 6.01 & 6.79 & 5.87 & 6.27 & 6.12 & 5.12 & 6.26 \\
\hline S.E. & 0.16 & 0.29 & 0.17 & 0.44 & 0.29 & 0.45 & 0.5 & 0.08 \\
\hline$\%$ & $1.7 \%$ & $2.3 \%$ & $3.4 \%$ & $1.6 \%$ & $4.2 \%$ & $2.8 \%$ & $5.9 \%$ & $2.8 \%$ \\
\hline \multicolumn{9}{|l|}{$\begin{array}{l}\text { Alcohol } \\
(0-11)\end{array}$} \\
\hline mean & 0.79 & 0.88 & 1.27 & 1.62 & 1.83 & 1.53 & 2.44 & 1.24 \\
\hline S.E. & 0.03 & 0.07 & 0.04 & 0.13 & 0.1 & 0.15 & 0.21 & 0.02 \\
\hline$\%$ & $2.2 \%$ & $4.3 \%$ & $8.6 \%$ & $12.8 \%$ & $18.5 \%$ & $15.6 \%$ & $27.7 \%$ & $8.8 \%$ \\
\hline \multicolumn{9}{|l|}{$\begin{array}{l}\text { Cannabis } \\
(0-40)\end{array}$} \\
\hline mean & 0.68 & 1.6 & 1.67 & 3.03 & 2.48 & 2.96 & 4.94 & 1.74 \\
\hline S.E. & 0.07 & 0.21 & 0.12 & 0.43 & 0.27 & 0.47 & 0.63 & 0.06 \\
\hline$\%$ & $1.7 \%$ & $6.9 \%$ & $8.0 \%$ & $13.8 \%$ & $12.7 \%$ & $14.1 \%$ & $21.4 \%$ & $7.8 \%$ \\
\hline \multicolumn{9}{|l|}{$\begin{array}{l}\text { Tobacco } \\
(0-10)\end{array}$} \\
\hline mean & 0.57 & 1.04 & 0.8 & 1.2 & 1.02 & 1.55 & 1.77 & 0.88 \\
\hline S.E. & 0.04 & 0.09 & 0.05 & 0.13 & 0.09 & 0.14 & 0.18 & 0.02 \\
\hline$\%$ & $10.8 \%$ & $20.0 \%$ & $15.1 \%$ & $23.7 \%$ & $17.8 \%$ & $28.8 \%$ & $31.5 \%$ & $16.5 \%$ \\
\hline \multicolumn{9}{|c|}{$\begin{array}{l}\text { Multiple } \\
\text { addictions }\end{array}$} \\
\hline mean & 0.23 & 0.52 & 0.68 & 1.08 & 1.31 & 1.35 & 2.19 & 0.7 \\
\hline S.E. & 0.02 & 0.04 & 0.03 & 0.08 & 0.06 & 0.09 & 0.11 & 0.01 \\
\hline \multicolumn{9}{|c|}{ At least one addiction } \\
\hline$\%$ & $20.4 \%$ & $40.1 \%$ & $48.3 \%$ & $61.0 \%$ & $68.3 \%$ & $67.8 \%$ & $88.6 \%$ & $44.9 \%$ \\
\hline
\end{tabular}

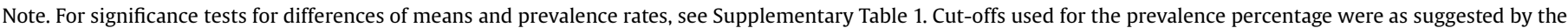

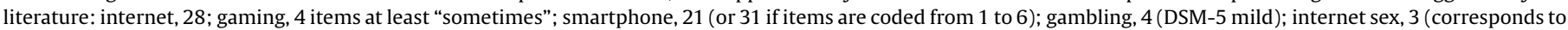

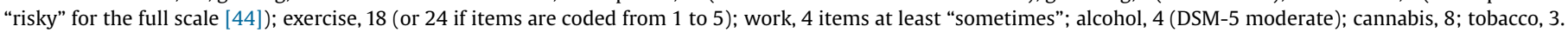

Values in brackets are the theoretical scale minimums and maximums.

\subsection{Limitations}

The main limitation is the restriction of the sample to men and to a restricted age range. Some addictions (e.g. internet related addictions, but also cannabis) tend to be reported more often in young age groups and men ([67-69]), and scale means and prevalence rates of most addictions might be substantially lower in general population samples, which also include older people and women. Furthermore, out of the seven behavioural addictions under investigation, only gambling is currently recognized as an addiction in DSM-5 [45], with the status of the others still being subject to some debate $[5,7,41]$.

Also, clearly more research is needed on the psychometric properties of the scales and appropriate cut-offs for estimating prevalence rates. Many of the included addiction scales are currently lacking cut-offs that were properly validated against a 


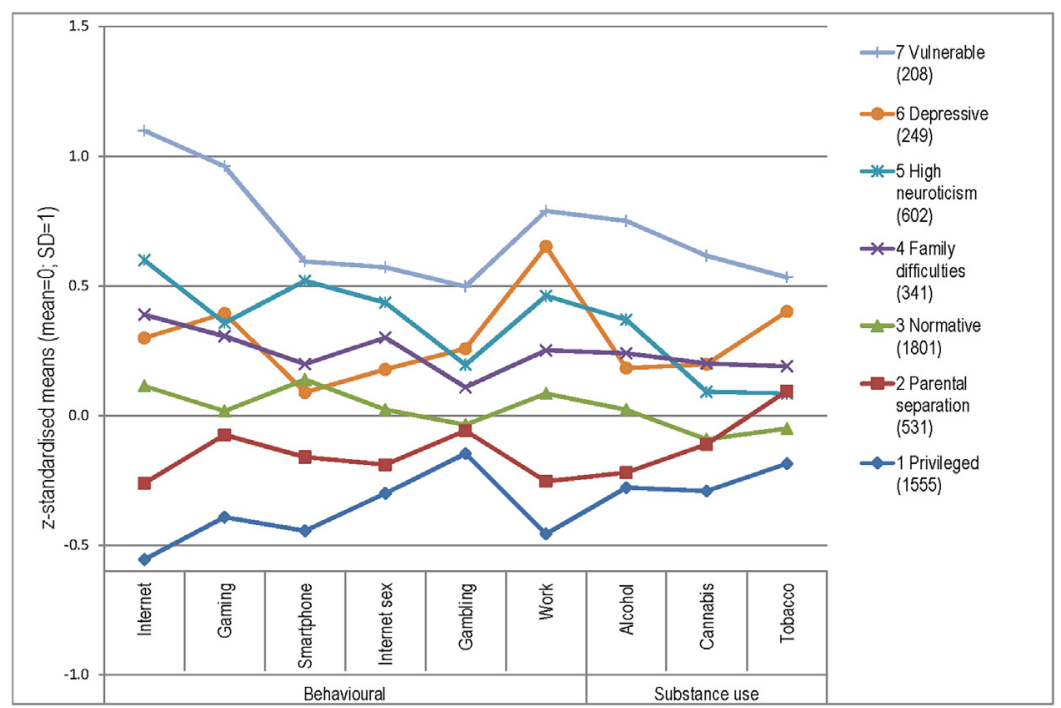

Fig. 2. Z-standardised means of behavioural and substance use disorder scales across profiles.

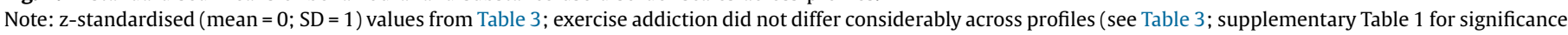
tests) and was not included in the figure because it would distort the figure.

Table 4

Summary of profile characteristics and mean values on the substance use disorders and behavioural addictions.

\begin{tabular}{|c|c|}
\hline Profile description & Substance use disorders and behavioural addictions \\
\hline \multicolumn{2}{|l|}{ Privileged (1) } \\
\hline $\begin{array}{l}\text { Generally favourable familial background (low rates of parental } \\
\text { separation, good relation to parents and good parenting), low } \\
\text { neuroticism/anxiety and aggression and high sociability personality } \\
\text { traits as well as better than average mental health. }\end{array}$ & Lowest values on all scales. \\
\hline \multicolumn{2}{|l|}{ Parental separation (2) } \\
\hline $\begin{array}{l}\text { High parental separation rates and high rates of a familial situation } \\
\text { with no or only one parent before the age of } 18 \text {, relationship with } \\
\text { parents before the age of } 18 \text { and parenting at the age of } 15 \text { close to } \\
\text { average, with values for personality and mental health being close to } \\
\text { profile } 1 \text {. }\end{array}$ & $\begin{array}{l}\text { Higher values than profile } 1 \text {, but still below profile } 3 \text { on all scales except } \\
\text { tobacco addiction. }\end{array}$ \\
\hline \multicolumn{2}{|l|}{ Normative (3) } \\
\hline Overall around the sample average on all scales. & Around the sample average on all addiction scales. \\
\hline \multicolumn{2}{|l|}{ Family difficulties (4) } \\
\hline $\begin{array}{l}\text { Bad relationships with parents before the age of } 18 \text { and low parenting } \\
\text { at age } 15 \text { combined with moderate rates of parental separation before the } \\
\text { age of } 18 \text {. Aggression personality trait was somewhat above average, while } \\
\text { sociability was rather low. Mental health was somewhat below average. }\end{array}$ & Values on addiction scales somewhat above profile 3. \\
\hline \multicolumn{2}{|l|}{ High neuroticism (5) } \\
\hline $\begin{array}{l}\text { High values on the neuroticism/anxiety personality trait, with somewhat } \\
\text { higher values on the aggression and lower values on the sociability traits. } \\
\text { Mental health was somewhat worse than average. }\end{array}$ & $\begin{array}{l}\text { High values on most addiction scales, particularly on technological addiction } \\
\text { scales, but not for cannabis and tobacco addiction, which were only little above } \\
\text { profile } 3 \text {. }\end{array}$ \\
\hline \multicolumn{2}{|l|}{ Depressive (6) } \\
\hline $\begin{array}{l}\text { High values on the depression scales and somewhat increased values } \\
\text { on the stress scale, while the other variables were close to average. }\end{array}$ & $\begin{array}{l}\text { Intermediary high values on addiction scales, except for smartphone addiction. } \\
\text { Values for gaming, work and tobacco addiction were especially high. }\end{array}$ \\
\hline \multicolumn{2}{|l|}{ Vulnerable (7) } \\
\hline $\begin{array}{l}\text { Worst mental health, highest neuroticism and aggression along } \\
\text { with lowest values on sociability personality traits, and below } \\
\text { average values for relationship with parents and parenting. }\end{array}$ & Highest values on all addiction scales, especially for internet and gaming addiction. \\
\hline
\end{tabular}

clinical gold standard. Furthermore, the present analysis was cross-sectional and therefore it was impossible to determine the causal direction of effects, e.g. whether poor mental health increased the risk of addictions or whether it was a consequence of an addiction. Poor mental health and addictions may also be both influenced by a third variable. Clearly, family background, personality and mental health variables are not specifically associated with addiction only. They may also influence each other and do not necessarily precede addiction.

\subsection{Conclusions}

SUDs and BAs are not isolated problems and purely a function of exposure to psychoactive substances or opportunities to engage in reinforcing behaviours. Instead, they are indeed deeply rooted in the individual's personal history, personality and vulnerability to mental health problems. This is independent of whether all of the discussed behaviours can be considered as "addictions" given the current state of research or just indicate problematic behaviours. It 
also seems likely that the different BAs and SUDs under investigation do share at least some common vulnerabilities. Furthermore, it is likely that at least some of the young men with mental health problems in our sample engaged in substance use or other reinforcing behaviours in order to cope with mental health problems. This also highlights the importance of treatment approaches which consider comorbid conditions and the persons general vulnerabilities, instead of focusing exclusively on a specific addictive disorder, which may leave underlying vulnerabilities unattended and thus prove unable to prevent relapse or a shift to another addiction. Examples of such treatment approaches, recently discussed in the context of addictive disorders, are integrated treatment $[70,71]$ and holistic treatment approaches [72].

\section{Declarations of competing interests}

None.

\section{Funding}

This study was funded by the Swiss National Science Foundation (FN 33CSC0-122679 and FN 33CS30-139467).

\section{Acknowledgments}

We wish to thank Celine Gachoud and Christiane Gmel for their valuable work in organising the study and collecting data.

\section{Appendix A. Supplementary data}

Supplementary data associated with this article can be found, in the online version, at https://doi.org/10.1016/j.eurpsy.2018.04.003.

\section{References}

[1] Shaffer H.J., LaPlante DA, LaBrie RA, Kidman RC, Donato AN, Stanton MV Toward a syndrome model of addiction: multiple expressions, common etiology. Harv Rev Psychiatry 2004;12:367-74.

[2] Gmel G, Akre C, Astudillo M, Bähler C, Baggio S, Bertholet N, et al. The Swiss cohort study on substance use risk factors - findings of two waves. Sucht 2015;61:251-62.

[3] Studer J, Baggio S, Mohler-Kuo M, Simon O, Daeppen J-B, Gmel G. Latent class analysis of gambling activities in a sample of young Swiss men: association with gambling problems, substance use outcomes, personality traits and coping strategies. J Gambling Stud 2016;32:421-40.

[4] Henchoz Y, Studer J, Deline S, N'Goran AA, Baggio S, Gmel G. Video gaming disorder and sport and exercise in emerging adulthood: a longitudinal study. Behav Med 2016;42:105-11.

[5] Kardefelt-Winther D, Heeren A, Schimmenti A, van Rooij A, Maurage P, Carras $\mathrm{M}$, et al. How can we conceptualize behavioural addiction without pathologizing common behaviours. Addiction 2017;112:1709-15.

[6] American Psychiatric Association. Diagnostic and statistical manual of mental disorders. 5th ed. Arlington, VA: American Psychiatric Publishing; 2013.

[7] Aarseth E, Bean AM, Boonen H, Colder Carras M, Coulson M, Das D, et al Scholars' open debate paper on the world health organization ICD-11 gaming disorder proposal. J Behav Addict 2017;6:267-70.

[8] Griffiths MA. 'Components' model of addiction within a biopsychosocial framework. J Subst Use 2005;10:191-7.

[9] Stone AL, Becker LG, Huber AM, Catalano RF. Review of risk and protective factors of substance use and problem use in emerging adulthood. Addict Behav 2012;37:747-75.

[10] Vachon J, Vitaro F, Wanner B, Tremblay RE. Adolescent gambling: relationships with parent gambling and parenting practices. Psychol Addict Behav 2004; $18: 398-401$

[11] Park SK, Kim JY, Cho CB. Prevalence of Internet addiction and correlations with family factors among South Korean adolescents. Adolescence 2008;43:895-909.

[12] Kotov R, Gamez W, Schmidt F, Watson D. Linking big personality traits to anxiety, depressive, and substance use disorders: a meta-analysis. Psychol Bul 2010;136:768-821.

[13] Andreassen CS, Griffiths MD, Gjertsen SR, Krossbakken E, Kvam S, Pallesen S The relationships between behavioral addictions and the five-factor model of personality. J Behav Addict 2013;2:90-9.
[14] Swendsen J, Conway KP, Degenhardt L, Glantz M, Jin R, Merikangas KR, et al. Mental disorders as risk factors for substance use, abuse and dependence: results from the 10-year follow-up of the National Comorbidity Survey. Addiction 2010:105:1117-28.

[15] Lieb R. Epidemiological perspectives on comorbidity between substance use disorders and other mental disorders. Co-occurring addictive and psychiatric disorders. Springer; 2015. p. 3-12.

[16] Ko $\mathrm{CH}$, Yen JY, Yen $\mathrm{CF}$, Chen $\mathrm{CS}$, Chen CC. The association between Internet addiction and psychiatric disorder: a review of the literature. Eur Psychiatry 2012;27:1-8.

[17] Schuckit MA. Comorbidity between substance use disorders and psychiatric conditions. Addiction 2006;101:76-88.

[18] Grant JE, Potenza MN, Weinstein A, Gorelick DA. Introduction to behavioral addictions. Am J Drug Alcohol Abuse 2010;36:233-41.

[19] Schluter MG, Hodgins DC, Wolfe J, Cameron Wild T. Can one simple questionnaire assess substance-related and behavioural addiction problems? Results of a proposed new screener for community epidemiology. Addiction 2018.

[20] Magidson J, Vermunt J. Latent class models for clustering: a comparison with K-means. Can J Market Res 2002;20:36-43.

[21] Hagenaars JA, McCutcheon AL. Applied latent class analysis. Cambridge University Press; 2002.

[22] Grant BF, Dawson DA, Stinson FS, Chou PS, Kay W, Pickering R. The Alcohol Use Disorder and Associated Disabilities Interview Schedule-IV (AUDADIS-IV): reliability of alcohol consumption, tobacco use, family history of depression and psychiatric diagnostic modules in a general population sample. Drug Alcohol Depend 2003;71:7-16.

[23] Hibell B, Guttormsson U, Ahlström S, Balakireva O, Bjarnason T, Kokkevi A, et al. The 2011 ESPAD report: substance use among students in 36 European countries. ESPAD; 2012.

[24] Aluja A, Rossier J, García LF, Angleitner A, Kuhlman M, Zuckerman M. A crosscultural shortened form of the ZKPQ (ZKPQ-50-cc) adapted to English, French, German, and Spanish languages. Pers Indiv Diff 2006;41:619-28.

[25] Hoyle RH, Stephenson MT, Palmgreen P, Lorch EP, Donohew RL. Reliability and validity of a brief measure of sensation seeking. Pers Indiv Diff 2002:32:401-14.

[26] Cohen S, Williamson GM. Perceived stress in a probability sample of the United States. In: Spacapan S, Oskamp S, editors. The Social Psychology of Health. Newbury Park, CA: Sage; 1988.

[27] Dalrymple K, Martinez J, Tepe E, Young D, Chelminski I, Morgan T, et al. A clinically useful social anxiety disorder outcome scale. Comprehens Psychiatry 2013;54:758-65.

[28] Zanarini MC, Vujanovic AA, Parachini EA, Boulanger JL, Frankenburg FR, Hennen J. A screening measure for BPD: the McLean screening instrument for borderline personality disorder (MSI-BPD). J Pers Disord 2003;17:568-73.

[29] Melartin T, Häkkinen M, Koivisto M, Suominen K, Isometsä E. Screening of psychiatric outpatients for borderline personality disorder with the McLean Screening Instrument for Borderline Personality Disorder (MSI-BPD). Nord J Psychiatry 2009;63:475-9.

[30] Kessler RC, Adler L, Ames M, Demler O, Faraone S, Hiripi E, et al. The World Health Organization adult ADHD self-report scale (ASRS): a short screening scale for use in the general population. Psychol Med 2005;35:245-56.

[31] Hirschfeld RMA, Williams JBW, Spitzer RL, Calabrese JR, Flynn L, Keck PEJ, et al. Development and validation of a screening instrument for bipolar spectrum disorder: the mood disorder questionnaire. Am J Psychiatry 2000;157:1873-5.

[32] Weber Rouget B, Gervasoni N, Dubuis V, Gex-Fabry M, Bondolfi G, Aubry J-M. Screening for bipolar disorders using a French version of the Mood Disorder Questionnaire (MDQ). J Affect Disord 2005;88:103-8.

[33] Bech P, Rasmussen NA, Olsen LR, Noerholm V, Abildgaard W. The sensitivity and specificity of the major depression inventory, using the present state examination as the index of diagnostic validity. J Affect Disord 2001;66:159-64.

[34] Meerkerk GJ, Van Den Eijnden RJJM, Vermulst AA, Garretsen HFL. The compulsive internet use scale (CIUS): some psychometric properties. Cyber Psychol Behav 2009;12:1-6.

[35] Meerkerk G-J, van den Eijnden RJ, Franken I, Garretsen H. Is compulsive internet use related to sensitivity to reward and punishment, and impulsivity. Comput Hum Behav 2010;26:729-35.

[36] Lemmens JS, Valkenburg PM, Peter J. Development and validation of a game addiction scale for adolescents. Media Psychol 2009;12:77-95.

[37] Kwon M, Kim D-J, Cho H, Yang S. The smartphone addiction scale: development and validation of a short version for adolescents. PLoS One 2014;8:e83558.

[38] Haug S, Paz Castro R, Kwon M, Filler A, Kowatsch T, Schaub MP. Smartphone use and smartphone addiction among young people in Switzerland. J Behav Addict 2015;4:299-307.

[39] Terry A, Szabo A, Griffiths M. The exercise addiction inventory: a new brief screening tool. Addict Res Theory. 2004;12:489-99.

[40] Andreassen CS, Griffiths MD, Hetland J, Pallesen S. Development of a work addiction scale. Scand J Psychol 2012;53:265-72.

[41] Griffiths MD, Demetrovics Z, Atroszko PA. Ten myths about work addiction. J Behav Addict 2018;1-13.

[42] Atroszko PA, Griffiths MD. Work addiction is not new to the psychological literature and has evolved over time. Global J Addict Rehabil Med 20173:

[43] Delmonico D, Miller J. The Internet Sex Screening Test: a comparison of sexual compulsives versus non-sexual compulsives. Sex Relat Ther 2003;18:261-76. 
[44] Carnes PJ, Delmonico DL, Griffin E. In the shadows of the net: Breaking free of compulsive online sexual behavior. Simon and Schuster; 2009.

[45] American Psychiatric Association. Diagnostic and statistical manual of mental disorders. 5th ed. Washington, DC: American Psychiatric Publishing; 2013.

[46] Office of Alcoholism and Substance Abuse Services DSM-IV Pathological Gambling Diagnostic Form. n.d.; http://www.oasas.ny.gov/gambling/ documents/822dsmivforweb.pdf (Accessed 10 September 2017).

[47] Knight JR, Wechsler H, Kuo M, Seibring M, Weitzman ER, Schuckit MA. Alcohol abuse and dependence among U: S. college students. J Stud Alcohol 2002;63:263-70.

[48] Annaheim B, Scotto TJ, Gmel G. Revising the cannabis use disorders identification test (CUDIT) by means of item response theory. Int J Methods Psychiatr Res 2010;19:142-55.

[49] Adamson SJ, Sellman JD. A prototype screening instrument for cannabis use disorder: the Cannabis Use Disorders Identification Test (CUDIT) in an alcoholdependent clinical sample. Drug Alcohol Rev 200322:.

[50] Heatherton TF, Kozlowski LT, Frecker RC, Fagerstrom K-O. The fagerström test for nicotine dependence: a revision of the fagerstrom tolerance questionnaire. Br J Addict 1991;86:1119-27.

[51] Muthen LK, Muthen BO. Mplus Version 8 User's Guide. Muthen \& Muthen; 2017.

[52] Nylund KL, Asparouhov T, Muthén BO. Deciding on the number of classes in latent class analysis and growth mixture modeling: a Monte Carlo simulation study. Struct Eq Model 2007;14:535-69.

[53] Bolck A, Croon M. Hagenaars J. Estimating latent structure models with categorical variables: one-step versus three-step estimators. Polit Anal 2004;12:3-27.

[54] Asparouhov TMB. Auxiliary Variables in Mixture Modeling: Using the $\mathrm{BCH}$ Method in Mplus to Estimate a Distal Outcome Model and an Arbitrary Secondary Model. Mplus Web Notes: No. 21. 2015.

[55] Lanza ST, Tan X, Bray BC. Latent class analysis with distal outcomes: a flexible model-based approach. Struct Eq Model: Multidiscipl J 2013;20:1-26.

[56] Blum K, Febo M, McLaughlin T, Cronjé FJ, Han D, Gold MS. Hatching the behavioral addiction egg: reward Deficiency Solution System (RDSS) ${ }^{\mathrm{TM}}$ as a function of dopaminergic neurogenetics and brain functional connectivity linking all addictions under a common rubric. J Behav Addict 2014;3:149-56.

[57] Ball SA. The validity of an alternative five-factor measure of personality in cocaine abusers. Psychol Assess 1995;7:148.
[58] Kotov R, Gamez W, Schmidt F, Watson D. Linking big personality traits to anxiety, depressive, and substance use disorders: a meta-analysis. Psychol Bull 2010;136:768-821.

[59] Ball SA. Personality traits, problems, and disorders: clinical applications to substance use disorders. J Res Pers 2005;39:84-102.

[60] Stone AL, Becker LG, Huber AM, Catalano RF. Review of risk and protective factors of substance use and problem use in emerging adulthood. Addict Behav 2012;37:747-75.

[61] Steiner S, Schori D, Gmel G. Excessive alcohol consumption in young men: is there an association with their earlier family situation? Swiss Med Wkly 2014; 144:w14007.

[62] Foxcroft DR, Lowe G. Adolescent drinking behaviour and family socialization factors: a meta-analysis. J Adolesc 1991;14:255-73.

[63] Kristjansson AL, Sigfusdottir ID, Allegrante JP, Helgason AR. Parental divorce and adolescent cigarette smoking and alcohol use: assessing the importance of family conflict. Acta Paediatrica. 2009;98:537-42.

[64] Caplan SE. Preference for online social interaction: a theory of problematic internet use and psychosocial well-being. Commun Res 2003;30:625-48.

[65] Caplan SE. Relations among loneliness, social anxiety, and problematic Internet use. Cyber Psychol Behav 2006;10:234-42.

[66] Lee BW, Stapinski LA. Seeking safety on the internet: relationship between social anxiety and problematic internet use. J Anxiety Disord 2012;26:197-205.

[67] Slade T, Teesson M, Mewton L, Memedovic S, Krueger RF. Do young adults interpret the DSM diagnostic criteria for alcohol use disorders as intended? A cognitive interviewing study. Alcohol: Clin Exp Res 2013;37:1001-7.

[68] Pabst A, Kraus L, Piontek D, Baumeister SE. Age differences in diagnostic criteria of DSM-IV alcohol dependence among adults with similar drinking behaviour. Addiction 2012;107:331-8.

[69] Marmet S, Gmel G. Suchtmonitoring Schweiz -Alkoholkonsumstörungen im Jahr 2013. Lausanne, Switzerland: Sucht Schweiz; 2014.

[70] van Wamel A, van Rooijen S, Kroon H. Integrated Treatment: The Model and European Experiences. Co-occurring Addictive and Psychiatric Disorders. Springer; 2015. p. 27-45.

[71] Morisano D, Babor TF, Robaina KA. Co-occurrence of substance use disorders with other psychiatric disorders: implications for treatment services. Nordic Stud Alcohol Drugs 2014;31:5-25.

[72] Dom G, Moggi F. Toward a New Model of Care: Integrating Mental Health, Substance Use, and Somatic Care. Co-occurring Addictive and Psychiatric Disorders. Springer; 2015. p. 375-89. 